\title{
NEKAJ MISLI O PRENOSU SPEKTRALNIH IDEJ V SLOVENSKI GLASBENI PROSTOR
}

\author{
LARISA VRHUNC \\ Filozofska fakulteta Univerze v Ljubljani
}

Izvleček: Članek se posveča skladateljskim skupinam po drugi svetovni vojni. Ob analizi njihove vloge $v$ razvoju skladateljskih praks poskuša poiskati odgovore na vprašanje, zakaj se spektralne ideje, ki so močno zaznamovale francosko in odmevale $v$ evropski glasbi od sedemdesetih let naprej, pri nas skorajda niso pojavile. Počasi vstopajo v našo glasbeno zavest šele v tem stoletju.

Ključne besede: slovenska glasba, glasba 20. in 21. stoletja, skladateljske skupine, spektralna glasba

\begin{abstract}
The article examines groups of composers who were active after the Second World War. An analysis of their role in the development of composition practices seeks to answer the question of why spectralism, which strongly marked French music and has resonated in European music ever since the 1970s, hardly emerged at all in Slovenia. It has slowly found its way into Slovenian musical consciousness only in the twenty-first century.
\end{abstract}

Keywords: Slovenian music, music of the twentieth and twenty-first centuries, composer associations, spectral music

V prispevku bomo skušali nakazati odgovore na dve vprašanji: zakaj se spektralne ideje v času svojega nastanka niso vsaj deloma manifestirale tudi pri nas in v kakšnih okoliščinah se je to nekaj desetletij zatem vendarle zgodilo. Pri iskanju odgovorov se je mogoče opreti na kratek zgodovinski pregled, ${ }^{1}$ osredotočen predvsem na tiste plasti slovenskega glasbenega življenja po drugi svetovni vojni, v katerih bi bilo mogoče vsaj bežno zaznati vzporednice s skupino francoskih nosilcev spektralnih idej.

\section{Obdobje po drugi svetovni vojni}

Kot drugod v Evropi je bila tudi v našem prostoru druga svetovna vojna tista ločnica, ki je pomembno preobrnila potek kulturne zgodovine. Vendar pa so bile posledice tega

1 S skladateljske perspektive je najtehtnejši zgodovinski pogled na obdobje med koncem druge svetovne vojne in slovensko osamosvojitvijo podal Lojze Lebič. Prim. Lebič, »Glasovi časov. O slovenski glasbeni ustvarjalnosti«. Morda največ o medvojnem obdobju pa izvemo v razpravi: Bogunović Hočevar, »Odmevi evropskih tendenc v ustvarjalnosti Janka Ravnika«, 24-41. 
preobrata pri nas precej drugačne kot $\mathrm{v}$ Zahodni Evropi. Zahodnoevropski skladatelji so se skušali oddaljiti od tistih glasbenih usmeritev, ki bi jih bilo mogoče povezati s predvojnim duhom nacističnih in fašističnih ideologij, in so se tako naslonili na pred vojno zamolčane ali pregnane napredne skladatelje, slovenski skladatelji pa so se takoj po vojni navezali predvsem na tiste ustvarjalce, ki so bili aktivni še pred delovanjem $\mathrm{k}$ novemu usmerjenih Marija Kogoja in Slavka Osterca. ${ }^{2}$ Tako kot drugod se je torej po drugi svetovni vojni tudi pri nas zgodil odklon od pred vojno začrtane poti glasbenega razvoja. ${ }^{3}$ Vendar pa je do neke mere to estetsko regresijo mogoče povezovati tudi z novonastalimi političnimi razmerami. Na Zahodu so si predvsem mladi skladatelji izborili veliko estetske svobode, s pomočjo katere naj bi se osvobodili tradicionalizma, v območjih, ki jih je zajel socialistični realizem, pa je politična oblast umetnost skušala izkoristiti za uresničevanje svojih ideoloških ciljev. ${ }^{4}$ Razmere za slovenske ustvarjalce niso bile tako trde kot drugod $\mathrm{v}$ vzhodnem bloku in politika se pravzaprav ni aktivno vmešavala, saj zaradi konservativne usmerjenosti večine ni prihajalo do neskladja z doktrino socialističnega realizma. Vendarle pa je bilo mogoče zaznati vsaj nesproščenost, če že ne (avto)cenzuro. ${ }^{5}$ Nazorna je na primer razprava o škodljivih vplivih jazza, ki se je zdel estetsko in ideološko kvaren in zato nesprejemljiv. Pri tem je zanimivo, da so kritike prihajale najprej iz vrst skladateljev resne glasbe in šele potem pedagogov, muzikologov in politikov. ${ }^{6}$ Gregor Pompe v svojem razmišljanju o povojnih tokovih meni, da je bila še največja težava $v$ kadrovski politiki, ki je omogočala, da so nekateri posamezniki pri vodenju kulturnih ustanov zelo na široko udejanjali svoja individualna estetska prepričanja in $\mathrm{s}$ tem usmerjali celotno glasbeno življenje. Najočitneje se to odraža v snovanju koncertnih sporedov in vzgoji mlajših generacij skladateljev.? To tezo podpira pričevanje Lojzeta Lebiča, ki v svojem

2 Prim. Pompe, »'Nove perspektive' v slovenski glasbi po letu 1945«, 247-248.

3 Tudi D. Cvetko ugotavlja, da se je ustvarjanje po drugi vojni nadaljevalo, a ne od tam, kjer je že bilo v tridesetih letih. Vzroke išče v prevladi socialističnega realizma, ki je glasbeno-tehnično in slogovno obstal v romantizmu. Prim. Cvetko, Slovenska glasba v evropskem prostoru, 422. Podobno poročajo tudi drugi raziskovalci, na primer Klemenčič, Slovenska glasba, 96.

4 Prim. Pompe, »'Nove perspektive'«, 248, in Lebič, »Glasovi časov«, 2:111. Ob tem velja omeniti, da je tudi na usmeritev zahodne umetnostne glasbe vplivala politika, tokrat zavezniška, ki je v povojni Nemčiji izdatno finančno podpirala napredne glasbene tokove, in sicer zato, ker tako usmerjeni skladatelji zagotovo niso imeli nikakršnih ideoloških povezav s predvojno Nemčijo. Prim. Ross, »Ura nič. Vojska ZDA in nemška glasba 1945-1949«, 367-378. Nekoliko romantizirano idejo o nemški povojni glasbi, ki je vstala kot ptič feniks iz ruševin razdejane dežele, je koristno dopolniti s še drugim razlogom za ameriško podporo (predvsem darmstadskim poletnim tečajem): s tem so Američani odprli pot svojim glasbenikom na evropska tla. Tako sta že zelo zgodaj v Nemčiji gostovala J. Cage in D. Tudor. Prim. Beal, »Negotiating cultural allies. American music in Darmstadt, 1946-1956«, 105-139.

5 Juš Kozak je npr. leta 1946 zapisal: »Priznajmo, zavladala je čudna, nezdrava tišina, ki je že v marsičem znak neke kulturne provincialnosti.« Citirano po delu: Koter, Slovenska glasba 1918-1991, 250. Umetnike, ki so prišli v nemilost, so doletele različne sankcije, na primer Zvonimirja Cigliča devet mesecev samice. Ibid., 254.

6 Prim. Kralj Bervar, »Sobivanje družbenega, stanovskega in umetniškega v zgodovini Društva slovenskih skladateljev«, 63-66. Morda bi lahko to dejstvo razumeli kot poskus merjenja moči med ustvarjalci samimi in boj za publiko z neglasbenimi sredstvi.

7 Pompe, »'Nove perspektive'«, 249-251. 
orisu povojne zgodovine glasbe navaja naslednje razloge za takratno stanje duha: poleg nazorske nesvobode in občutka ogroženosti, ${ }^{8}$ pomanjkanja zgodovinskega spomina in narodne zavesti ter umanjkanja meščanske kulture se mu zdita poglavitna padec ravni glasbene vzgoje in predvsem prekinjen dotok virov in informacij. Obdobje petnajstletne izolacije je po njegovem mnenju povzročilo tolikšen mišljenjski primanjkljaj, da ga niti kasnejši naprednejši tokovi niso zmogli v celoti nadomestiti. ${ }^{9}$ Za ilustracijo lahko služi primerjava najvidnejših dosežkov z začetka petdesetih let: pri nas so nastajala simfonična dela (M. Lipovšek, P. Ramovš, D. Škerl), tehnično dovršene skladbe po vzoru neoklasicističnih del Sergeja Prokofjeva in v zvrsteh, značilnih za 19. in začetek 20. stoletja, medtem ko sta bili v istem času v Darmstadtu predstavljeni na primer prelomni deli Struktures Ia (Strukture Ia) Pierra Bouleza in Music of Changes (Glasba premen) Johna Cagea. ${ }^{10}$ Konglomerat vseh navedenih dejavnikov je privedel do tega, da so nekateri slovenski skladatelji po koncu druge svetovne vojne prenehali ustvarjati, drugi so spremenili svoja estetska stališča, le manjši del skladateljev pa je nadaljeval po prej začrtanih poteh.

\section{Skupine skladateljev}

Predvojno glasbeno življenje je temeljilo na glasbenih združenjih, ki so spodbujala zdravo kulturno klimo, po vojni pa te vloge ni zares prevzela nobena od novonastalih institucij. Zato je mogoče opazovati občasno porajanje »civilnih združb « ${ }^{11}$, ki se niso formirale na osnovi pripadnosti kakšni določeni estetski usmeritvi, ampak je bila njihova naloga promocija novonastalih slovenskih del ali pa zapolnjevanje vrzeli v letih intenzivnejše izolacije, največkrat pa kombinacija obojega.

\section{Dijaki Jurija Gregorca in Klub komponistov}

Prvo tako združenje je izraslo iz kompozicijskih večerov dijakov Jurija Gregorca, ki je dijake teoretskega oddelka srednje glasbene šole navduševal za skladanje. Po koncertih leta 1952 in 1953 so se leto kasneje bivši dijaki, zdaj študenti, na lastno pobudo združili v pravo skladateljsko skupino z imenom Klub komponistov. Pobudo zanj je dal Ivo Petrić, ki je predlagal, da bi po vzoru večerov dijakov mladi skladatelji sami pripravljali koncerte z izvedbami lastnih del. Ob tem pa ni šlo le za priložnosti za izvedbe, ampak tudi za boj za obstoj, potrditev v okviru skupine, ki je ne bi bilo mogoče spregledati, zavzemali pa so se tudi za pravico do drugačnih estetskih prepričanj, kot so jih zagovarjali njihovi profesorji, predvsem Lucijan Marija Škerjanc, ki ga dela študentov niso niti malo zanimala ali jim

8 Podobne misli je zaslediti tudi pri Klemenčiču: opaža ideologiziranost in neavtonomnost slovenskega glasbenega prostora in med najškodljivejšimi posledicami navede kadrovski nadzor, cenzuro in samocenzuro. Prim. Klemenčič, Slovenska glasba, 95.

9 Lebič, »Glasovi časov«, 2:111-112.

${ }^{10}$ Pompe, »'Nove perspektive'«, 251.

${ }^{11}$ Lebič, »Glasovi časov«, 2:111. 
je celo nasprotoval ter jih $\mathrm{s}$ tem prisilil $\mathrm{v}$ iskanje drugih poti za pridobivanje znanja in izkušenj. ${ }^{12}$ Tedanji člani kluba so kot edina relevantna sodobnika tako omenjali Uroša Kreka in Primoža Ramovša, kot vzornika pa predvsem S. Osterca, ki je veljal za odločnega nasprotnika L. M. Škerjanca. ${ }^{13}$ Zbirali so se predvsem kot študenti kompozicije in sta jih združevali generacijska pripadnost ter skupni interes za izvajanje njihovih lastnih del, ne pa tudi kakršne koli slogovne težnje ali celo podobnosti glasbenega izraza, česar so se zavedali tudi sami. ${ }^{14}$

Klub komponistov je ob koncu petdesetih let postopoma ugasnil, ko se je razblinila iluzija o povezovalni moči skupnih interesov in ko sta $\mathrm{v}$ njem prenehala sodelovati dva vodilna člana, Ivo Petrić in Alojz Srebotnjak. ${ }^{15} \mathrm{~V}$ tej praznini se je pojavila sekcija Muzika 59, zanjo je skrbel Igor Štuhec, ki je v tem času zaključeval študij kompozicije v Ljubljani. Z nekaj somišljeniki je želel nadaljevati tradicijo organiziranja koncertov z deli mladih skladateljev, a neuspešno. Sekcijo je torej vredno omeniti predvsem zato, ker kaže na potrebo in željo po načinu združevanja mladih skladateljev v skupine, kakršna je bila Klub komponistov. ${ }^{16}$

\section{Collegium musicum}

Druga skupina, ki sicer ni bila sestavljena samo iz skladateljev, je pa pomembno pripomogla k uveljavljanju novih estetskih tokov, je Collegium musicum. Leta 1957 jo je ustanovil Pavel Šivic. Iz koncertnih sporedov je razvidno, da cilj združenja ni bil, predstaviti javnosti najsodobnejše evropske ideje, ki so se širile iz večjih evropskih centrov, ampak jo predvsem seznanjati z že kanoniziranimi deli, ki jih pri nas še nismo poznali. Skupina ni bila samostojna, ampak je delovala kot skupna delovna sekcija več glasbenih društev, med njimi tudi Društva slovenskih skladateljev. ${ }^{17}$ Zato ne preseneča, da so v koncertne sporede vključevali tudi predstavitve novonastalih slovenskih del. Dejstvo je, da si je P. Šivic prizadeval vključevati dela mlajših skladateljev, vendar predvsem tista, ki so blizu osterčevski modernistični maniri. ${ }^{18}$ Sporedi Collegiuma so posebej pomembni,

${ }^{12}$ Prim. Loparnik, »Pogovor z Janezom Matičičem«, 1470. Matičič je povedal, da je L. M. Škerjanc "mojstre, ki so bili že pred vojno znani in aktualni [...] očrnil kot skladatelje, ki nas nimajo česar naučiti, ne tehnično ne estetsko«. Zelo kritičen do učiteljske vloge Škerjanca je bil tudi I. Petrić. Prim. Barbo, Pro musica viva, 42.

${ }^{13}$ Ibid., 40-42.

${ }^{14}$ Ibid., 53.

${ }^{15}$ Ibid., 55-56.

${ }^{16}$ Ibid., 64-65.

${ }^{17}$ Kralj Bervar, »Sobivanje družbenega, stanovskega in umetniškega v zgodovini Društva slovenskih skladateljev«, 96 in 202. Avtorica sicer navaja, da je bil cilj skupine predstaviti »najsodobnejša domača in mednarodna glasbena iskanja«, a prvi koncert je bil posvečen že več kot desetletje preminulemu B. Bartóku, drugi pa P. Hindemithu, ki je bil na koncu svoje umetniške in življenjske poti in je svojo vplivno teorijo glasbenega stavka objavil že v tridesetih letih. Podobno velja za ostale predstavitve tuje glasbe, so pa bili vsaj nekateri izmed teh koncertov odmevni in so odločilno vplivali na naše razmere. Prim. Barbo, Pro musica viva, 58.

${ }^{18}$ Ibid., 58. 
ker so tvorili nekakšen most med programi uradnih institucij, ki so sodobne slovenske skladbe večinoma spregledovale, in tistimi, ki jih je oblikovala deloma sočasno delujoča in na videz nekoliko jasneje estetsko profilirana skupina Pro musica viva (PMV). ${ }^{19}$ Poleg izvajanja pri nas še nepoznanih tujih in domačih del je delovanje Collegiuma pomembno tudi zato, ker je v povezavi z zvezo Svoboda po vsej Sloveniji prirejal koncerte z izrazito izobraževalno vlogo: izvedene skladbe so bile tudi razložene. ${ }^{20}$ Po desetletju uspešnega delovanja je Pavel Šivic ugotovil, da so se razmere z ustanovitvijo drugih platform(PMV, Ansambel Slavka Osterca in še nekateri drugi sestavi, festivali sodobne glasbe - predvsem v Zagrebu in Varšavi, pa tudi v Radencih in Opatiji) toliko izboljšale, da Collegium lahko preneha delovati, saj je uspešno opravil svoje poslanstvo. ${ }^{21}$

Razloge, da je bilo delovanje tovrstnih skupin mogoče, gre iskati med drugim v prvem obdobju politične odjuge: Jugoslavija je po letu 1953 prehajala v čas državno vodene politike $\mathrm{z}$ mehkejšimi prijemi. ${ }^{22} \mathrm{~V}$ takem družbenem ozračju se je lahko zgodil obrat k subjektivizmu, in sicer najprej v literaturi, pa tudi v likovni umetnosti. V glasbi se poleg združevanja v skupine izboljšanje razmer kaže tudi v utrditvi vloge RTV Ljubljana $\mathrm{z}$ na novo ustanovljenim simfoničnim orkestrom ter mladinskim in komornim zborom, $\mathrm{v}$ nastanku Slovenske glasbene revije, ki je z notnim in znanstveno zasnovanim besedilnim delom želela nadaljevati tam, kjer sta pred vojno obstali reviji Novi akordi in kasneje Nova muzika, ter v utemeljitvi Edicij DSS. ${ }^{23}$

\section{Pro musica viva}

Na usedlinah razcveta $\mathrm{v}$ petdesetih letih se je okrog leta $1960^{24}$ pojavila skupina Pro musica viva, ki jo lahko razumemo kot do sedaj najpomembnejši poskus združevanja napredno usmerjenih skladateljev. Razlogi, ki so mlade ustvarjalce (večinoma nekdanje člane Kluba komponistov) pripeljali do ustanovitve te skupine, so zelo podobni tistim, ki so botrovali že nastanku Kluba: želeli so si več možnosti za izvajanje, snemanje in natise svojih del, motilo pa jih je tudi nespodbudno okolje, v katerem tudi ni mogel živeti spomin na predvojne dosežke slovenskih skladateljev, predvsem M. Kogoja in S. Osterca. Še bolj pereče pa je bilo pomanjkanje pretoka idej in informacij iz širšega evropskega prostora. Pregled sporedov prvih koncertov pokaže, da so sicer na njih prevladovala dela

${ }^{19}$ Ibid., 61.

${ }^{20} \mathrm{Na}$ zavedanje pomembnosti izobraževanja publike kaže tudi osnutek statuta PMV, v praksi pa skupina tega ni udejanjala v tolikšni meri kot Collegium.

${ }^{21}$ Kralj Bervar, »Sobivanje družbenega, stanovskega in umetniškega v zgodovini Društva slovenskih skladateljev«, 202.

${ }^{22}$ Ibid., 72.

${ }^{23}$ Lebič, »Glasovi časov«, 2:116-117; prim. Kralj Bervar, »Sobivanje družbenega, stanovskega in umetniškega v zgodovini Društva slovenskih skladateljev«, 90-91 in 116-117.

${ }^{24}$ Barbo navaja, da so k ideji o ustanovitvi skupine prispevale različne pobude, načrtovana in naključna srečanja, posamezna dejanja in sklepi, ki jih nihče ni sistematično beležil. Prvi zanesljivi datum je dan prvega koncerta, 10. januar 1962, gotovo pa so se sestajali že vsaj leto pred tem. Prim. Barbo, Pro musica viva, 79-80. 
članov skupine, vendar pa so že na drugem koncertu predstavili tudi Kogojeve samospeve, poleg tega pa so nadaljevali z izvajanjem pri nas še nepoznanih del velikanov glasbe 20 . stoletja in tako zapolnjevali recepcijsko vrzel, ki je nastala med vsaj desetletno izolacijo. ${ }^{25}$ Za razumevanje vloge skupine je pomembno ugotoviti, da se je od svoje predhodnice Kluba komponistov razlikovala predvsem po tem, da članstvo v PMV ni bilo odprto vsem mladim skladateljem, torej samo glede na generacijsko pripadnost, ampak je bila potrebna vsaj deklarativna zavezanost estetskim izhodiščem, ki so jih označevali z izrazom »sodobna«. ${ }^{26}$ Še jasneje je to razvidno iz osnutka statuta skupine. Čeprav dokument ni bil nikoli sprejet, ga zaradi jasno izraženih estetskih stališč, programa in ciljev lahko razumemo kot »manifest $«,{ }^{27}$ kar je tudi edini poskus jasnejšega (samo)opredeljevanja v povojni zgodovini slovenske glasbe. Iz dokumenta, ki ga je zasnoval Jakob Jež, je razvidno, katera vprašanja so se vsaj avtorju osnutka zdela pomembna. Kaže, da si ostali člani niso želeli tako natančno določiti vseh podrobnosti, gotovo tudi zaradi vsebinskih razhajanj. Kot smoter delovanja skupine je navedeno ustvarjanje in širjenje sodobne glasbe, pri čemer je slogovna in estetska usmeritev članov svobodna (s pripisom, da mora vendarle biti sodobna). Sodobnost gre razumeti kot estetski pojem, a ne afirmativnega značaja, ampak kot negacijo starega. Iz tega lahko sklepamo, da so se člani strinjali na idejni ravni (odmik od starega), njihove kompozicijsko-tehnične rešitve in osebne poetike pa so se precej razlikovale. Vsak skladatelj si je namreč iz posameznih neurejenih drobcev ustvaril nehomogeno sliko ter lastni nabor svojim estetskim potrebam prirejenih izraznih sredstev in tehnik. Stanje gre pripisati nezadovoljivemu šolskemu sistemu, razpršenosti informacij in omejenemu razgledu po svetu. ${ }^{28}$ Nadaljevanje osnutka statuta ureja praktične vidike delovanja: na kateri način bodo sprejemali sklepe, kako jih bodo izvajali, kako je s članstvom, v kakšnih okoliščinah lahko to preneha in kako si bodo delili delovne naloge, posebej glede organizacije koncertov. V celoti so prečrtani členi, ki se nanašajo na kvaliteto delovanja, izobraževanje javnosti in izvajalsko telo, ki je bilo v času nastanka osnutka še sestavni del skupine in je tudi nosilo njeno ime. ${ }^{29}$

Skupina Pro musica viva se je konec šestdesetih let postopoma razšla. Spori so se stopnjevali predvsem zato, ker so člani v tem času postali zreli in v uradnem prostoru dobro uveljavljeni avtorji in potreb po skupnem nastopanju ni bilo več.

Tik pred koncem delovanja so se še združili, da so izdali skupinsko LP ploščo s svojimi deli. Izid plošče je pomemben zato, ker gre za prvo tovrstno predstavitev slovenske

${ }^{25}$ Najprej so bila predstavljena dela K. Pendereckega, H. W. Henzeja, E. Varèsea in I. Stravinskega. Tudi sicer je opaziti, da so prevladovala slovenska dela, tuja pa so bila v manjšini, vendar redno prisotna. Prim. Barbo, Pro musica viva, 94-109.

${ }^{26}$ Ibid., 53.

${ }^{27}$ Prim. ibid., 80-94.

${ }^{28}$ Ibid., 87.

${ }^{29}$ J. Jež o začetkih ansambla: »Pokazala se je potreba, da bi imeli za svojo glasbo tudi svoj ansambel. In res, tak ad hoc ansambel smo po zaslugi Iva Petrića, ki je bil odličen organizator, kmalu tudi dobili. [...] Sprva je Petrićev ansambel nastopal pod istim imenom [PMV], ko pa je njegov vodja vse bolj po svoje krojil program, s(m)o se 'promusikaši' uprli, češ, da to ni več realizator naše programske volje.« Gačeša, »Pro musica viva«, 50. Ansambel se je zato leta 1963 osamosvojil in si nadel ime Slavko Osterc, še vedno pod vodstvom I. Petrića. 
umetnostne glasbe, pa tudi, ker ga lahko razumemo kot predlog kulturni politiki, kako skrbeti za uveljavljanje slovenskih del in glasbenikov. ${ }^{30}$

L. Lebič pomen delovanja skupine opredeli tako:

Temeljnih slovenskih dilem - glasba kot mišljenje ali čustvo, racionalnost ali spontanost, tradicionalizem ali modernizem - tudi PMV ni znala rešiti. Niti znotraj sebe. Modernizmu se je pridružila prepozno, ko je v svetu že izzvenel, ko so vsa drzna odkritja in raziskave že bile opravljene drugje. Kljub temu, da PMV in somišljeniki zunaj nje niso uresničili vseh napovedi in ne izkoristili vseh možnosti, so bila šestdeseta leta čas največje bližine in sozvočja slovenske povojne glasbe $\mathrm{z}$ evropsko. ${ }^{31}$

Moderniziranje slovenske glasbene ustvarjalnosti se ni dogajalo le znotraj PMV, ampak so k temu prispevali tudi nekateri starejši in že uveljavljeni skladatelji, predvsem Pavle Merkù, Pavel Šivic in Primož Ramovš. Najdlje med njimi je stopil slednji: preizkušal je celó totalno serializacijo in jo v letu 1963 tudi udejanjil v skladbi Pentektasis. Njegov opus je zanimiv tudi zato, ker v njem ni opaziti velikih slogovnih nihanj ali retrogradnih tendenc, kot je značilno za večji del skladateljev iz skupine PMV.L. Lebič ga je opredelil kot samohodca, pri katerem sta po letu 1968, ko je dokončno izoblikoval lastni slog, prisotna »samoironičen odmev neoklasicistične preteklosti« in ustvarjanje »s polnim zaupanjem v zvok kot edini temelj sveta «. ${ }^{32}$ Poleg v novo usmerjenih avtorjev je pomembno ustvarjanje Uroša Kreka kot tistega skladatelja, katerega dela »kompozicijsko tehnično prihajajo izpred modernizma «, ${ }^{33}$ a so tehtna. Velja omeniti še skladatelje, ki so takrat že delovali v tujini: Vinko Globokar, Janez Matičič, Božidar Kantušer, Božidar Kos, Janko Jezovšek. Nihče med njimi ni neposredno opazneje vplival na glasbeno življenje v Sloveniji, pomembni pa so zato, ker njihovi opusi dokazujejo, da dlje trajajoči stiki s kulturno bolj odprtimi okolji vodijo do večje svobode in drznosti pri prečiščevanju glasbenih sredstev in poetik. ${ }^{34}$

Po koncu delovanja PMV se je v slovenskem glasbenem prostoru postopoma uveljavljala estetska mnogovrstnost. Politika je spet začela vstopati v umetniško sfero (začetek »svinčenih let«) in posledično onemogočala nadaljnje združevanje skladateljev na osnovi novih estetskih izhodišč. Ustvarjalci so se umikali v zasebnost, v kateri so našli več ustvarjalnega miru in svobode, ali pa so pristali na konformizem. L. Lebič kot enega od nosilcev politizacije glasbe omenja Marijana Gabrijelčiča, ki je pred tem že odigral precej negativno vlogo kot kritik dogajanj okrog PMV, idejno pa je »očistil« tudi Slovensko filharmonijo, ko je leta 1975 postal njen umetniški vodja. Razlogi za postopen umik v »idealiziran, od življenja manj moten svet « ${ }^{35}$ pa so še drugje: že ob koncu šestdesetih let so se povsod po svetu dosežki modernizma začeli umikati različnim individualnim iskanjem poti k sebi. G. Pompe ta dogajanja postavi v začetek osemdesetih let in ugotovi, da je okolje, ki ni zares

${ }^{30}$ Barbo, Pro musica viva, 106-107. Plošča je izšla leta 1966.

${ }^{31}$ Lebič, »Glasovi časov«, 3:5. Članek je bil napisan v letih 1993 in 1994, ko se še ni pojavil novi val v tujini šolajočih se mladih skladateljev.

32 Ibid., 1.

${ }^{33}$ Ibid., 3.

${ }^{34}$ Prim. ibid., 1-2, in Pompe, »'Nove perspektive'«, 257-258.

${ }^{35}$ Lebič, »Glasovi časov«, 4:59. 
doživelo glasbene katarze prvega vala modernizma, toliko raje sprejelo postmodernistične tendence, vendar s precej samosvojimi potezami. ${ }^{36}$ Za slovensko ustvarjalnost namreč ni značilno sopostavljanje modernističnega in tradicionalnega in iskanje novih pomenskih ravni v trenjih med obema poloma, ampak gre bolj za »vračanje«, nereflektirano prevzemanje tradicionalnih vzorcev, ${ }^{37}$ mestoma celo vzorcev iz popularne glasbe ${ }^{38}$ in njihovo poljubno združevanje. Modernistični pol, proti kateremu bi bilo tradicionalne okruške mogoče postaviti, pri nas večinoma umanjka. V takem ozračju se pojavi nova generacija ustvarjalcev, L. Lebič jo imenuje »vmesna «, ${ }^{39}$ ki ne čuti potrebe, da bi se opredeljevala do radikalizma prejšnjih generacij, pa tudi ne do ustvarjalnosti sodobnikov. Iz te generacije omenimo, poleg tistih, ki so odšli v tujino, predvsem Bora Turela, ki je v tistem času edini predstavnik post-cageevskih in minimalističnih idej, Alda Kumarja in Marka Mihevca, ki sta se vsaj na začetku najbolj izrazito odprla postmodernizmu, in Brino Jež Brezavšček ter Tomaža Sveteta, ki sta poskušala nadaljevati po poti PMV. Sedemdeseta in osemdeseta leta pri nas torej zaznamuje razpršenost skladateljskih iskanj. Zarezo v to »letargično« stanje prinese osamosvojitev Slovenije.

\section{Muzina}

Ob slovenski osamosvojitvi in vojnah na ozemlju nekdanje skupne države so se prekinili stiki z jugoslovanskimi glasbenimi institucijami, kar je povzročilo izrazito zožitev glasbenega prostora, ki je nazadoval že v letih pred tem. ${ }^{40}$ Nastanek Društva za spodbujanje in napredek nove glasbe Muzina gre torej razumeti kot reakcijo na novonastalo stanje. O razlogih za nastanek in o načinu delovanja največ izvemo iz intervjuja z Brino Jež Brezavšček - ustanoviteljico društva, ki je začelo delovati leta 1991:

Za nastanek društev ${ }^{41}$ sem dala pobudo sama in jih nato tudi vodila, oziroma, rekli bi, ostala sama z goščavo dodatnega birokratskega in vsega drugega dela, ki ga na koncertnih agencijah opravlja mnogo ljudi. [...] Pri Muzini je sodelovala Mirjam Žgavec [...]. Šlo je za to, da po osamosvojitvi v novi državi niso bili vzpostavljeni sistemi predstavljanja sodobne glasbe, kamor bi kot mlada avtorica brez težav lahko prijavljala dela na razpis, kot je bilo to skladateljem omogočeno v Jugoslaviji, se pravi na Tribunah glasbenega ustvarjanja v Opatiji na Hrvaškem. [...] Poleg tega pa v Sloveniji skorajda ni bilo možno slišati komornih skupin, ki izvajajo sodobno glasbo, iz mednarodnega prostora. [...] (K)oncerti

${ }^{36}$ Enako L. Stefanija. Govori o tretji premeni v zgodovini slovenske glasbe 20. stoletja, ki naj bi slonela na »pogostem ugotavljanju 'izgube' jasnih umetniških meril in ustvarjalnih vodil«. Stefanija, Prispevek k analizi institucij slovenske glasbe 20. stoletja, 50.

${ }^{37}$ Lebič, »Glasovi časov«, 4:61.

${ }^{38}$ Pompe, »Nove perspektive«, 260.

${ }^{39}$ Lebič, »Glasovi časov«, 4:59.

${ }^{40}$ L. Lebič poroča za osemdeseta leta, da preveč naših skladateljev ostaja v tujini, Akademija za glasbo niti ne poskuša navezati stikov z njimi, odločilna mesta pripadajo hermetično zaprtemu krogu izbrancev, ni nobenega skladateljskega srečanja in nobene prireditve, ki bi ponujala sveže informacije o dogajanjih v tujini. Prim. Lebič, »Glasovi časov«, 4:62-63.

${ }^{41} \mathrm{~V}$ mislih ima še društvi Sirius AB in Sozven, ki ju je ustanovila po zatonu Muzine. 
so bili [...] vedno pospremljeni tudi s kritikami, ki jih je bilo takrat v dnevnem časopisju sicer res precej več kot danes, vendar pa so vsote financiranja ostajale na minimumu, ki je zahteval, da prav vse malenkosti opraviva sami z Mirjam, ker pa sem bila na tem področju bolj domača, bi rekla, da je bilo še precej več dela na moji strani. [...] (Z)bolevala sem in društvo končno ukinila. No in potem zopet ta nemoč. Ne da se kreirati svojih realizacij, uklanjati se je treba le danim naročilom, večkrat polovičarstvu v izvajalski praksi, saj mnogi izvajalci tej glasbi niso naklonjeni in jo igrajo zaradi prestiža in morda honorarja. ${ }^{42}$

Kot je razvidno že iz imena društva, je bil njegov namen prirejati koncerte »nove, sodobne glasbe $\ll^{43} \mathrm{z}$ deli domačih in tujih skladateljev. Muzina je imela svoje izvajalsko telo, Godalni kvartet za novo glasbo Muzina, ki je tvoril izvajalsko jedro društvenih koncertov. Ta praksa je vsaj pri nas značilna za drugo polovico 20 . stoletja. ${ }^{44}$ Društvo si je tudi prizadevalo privabiti tuje uveljavljene izvajalce sodobne glasbe, česar takoj po osamosvojitvi druge institucije niso opravljale. Kot dosežke Muzine gre omeniti tudi serijo koncertov elektroakustične glasbe, kar je bil pri nas še vedno precej redek pojav. Morda velja izpostaviti še dogodek v Galeriji Škuc, ${ }^{45}$ katerega namen je bil združiti glasbeno in vizualno umetnost (to idejo smo srečali že ob ustanovitvi KA, le da je bil pri tem projektu stik med sodelujočimi bolj neposreden).

Pri Muzini v resnici ne gre za pravo skladateljsko skupino, ampak bolj za društvo, ki ga je poganjala ena sama oseba. Čeprav koncertni sporedi razkrivajo, da je Muzini uspelo v Ljubljano povabiti nekatere vrhunske izvajalce (na primer dunajski Klangforum, ki je pri nas prvi predstavil glasbo Giacinta Scelsija, ali pa violončelista Rohana de Sarama), hkrati kažejo tudi na nesorazmerno zastopanost avtorjev, ki bi se glede na estetske usmeritve Muzini lahko tvorneje pridružili. Poleg voditeljice društva se posebej v kontekstu elektroakustične glasbe pojavljata še Bor Turel in Marijan Šijanec, za katera sama pravi, da sta bila edina, na katerih pomoč je lahko računala. ${ }^{46}$ Morda je škoda, da ji ni uspelo razširiti kroga somišljenikov, saj so bili nastavki dobri. V pogovoru Brina Jež Brezavšček pravi: »Muzina je bila takrat prvo glasbeno društvo, nastalo po privatni iniciativi in v takem manjšem obsegu. Poleg tega je šlo za predstavljanje mlajših avtorjev, vse to je bilo

42 Škrlj, »Pedagoški portret slovenske skladateljice Brine Jež Brezavšček«, 56-57.

${ }^{43}$ Ibid., 13.

${ }^{44}$ Razen Kluba komponistov in Collegiuma, katerega članice so bile tudi združenja izvajalcev, lahko sledimo tem vzporednicam: PMV - ansambel PMV, ki se je sicer še v času delovanja skupine osamosvojil in preimenoval v Ansambel Slavko Osterc ter postal osrednje izvajalsko telo festivala v Radencih; Muzina - godalni kvartet Muzina; Glasbeno društvo Slowind - Pihalni kvintet Slowind, pri čemer velja omeniti, da je oboje navezano še na Festival Slowind, omenimo pa lahko še dva ansambla, ki sta vezana na festivale in ne na društva: Unicum - MD7 in Predihano - Neofonía.

${ }^{45}$ Novica STA: »Paralelni svetovi kot inštalacija, glasba, razstava in okrogla miza: dogodek bo v Galeriji Škuc 12. in 13.10.1993. Sodelujoči: skladatelji Brina Jež Brezavšček, Neville Hall, Marijan Šijanec, Bor Turel, slikarki Nataša Pičman, Gordana Novaković in kiparka Nika Špan.« (Splet, obiskano 31. 7. 2016.)

${ }^{46}$ Franc Križnar sicer med najkreativnjše člane uvrsti še Igorja Štuheca in Igorja Majcna. Prim. Križnar, »Poskus diagnoze sodobne slovenske glasbene umetnosti«, 40. 
bolj zanimivo tudi medijsko in smo bili deležni večje pozornosti.« ${ }^{47}$ Leta $2000^{48}$ je vodenje društva predala mladima muzikologoma Gregorju Pompetu kot predsedniku in Urški Šramel Vučina kot podpredsednici, zadolženi predvsem za organizacijsko plat festivala Muzifest, ki je prvič potekal leta 1999. Po nekajletnem delovanju pod novim vodstvom sta tako društvo kot festival ugasnila. ${ }^{49}$ Da je bila Muzina kljub pomanjkljivostim pomemben mejnik v slovenskem glasbenem življenju, pričajo žolčni kritiški zapisi Franca Križnarja, ki ga je najbolj motila elektroakustična glasba. ${ }^{50} \mathrm{~V}$ resnici je iz zapisov razvidno predvsem to, da je bil zgodovinski spomin na dosežke PMV v obdobju »svinčenih let« skoraj popolnoma izbrisan. Zanimiv je tudi drugi Križnarjev »poskus diagnoze«, v katerem ugotavlja, da je bil koncert prvega Muzifesta s slovenskimi novitetami »odlično obiskan« in »zadetek v polno, [...] več kot očitna (pa) je bila odsotnost 'uradnega' zastopstva DSS [...] in [...] 'uradne' stroke z oddelka za kompozicijo in glasbeno teorijo ljubljanske AG «. ${ }^{51}$ Stanje je bilo torej precej podobno tistemu, ki ga uteleša Škerjančev čas.

\section{Komentarji}

Pregled delovanja združb znotraj umetnostne glasbe po drugi svetovni vojni kaže, da je bila PMV edina skupina, ki se je formirala na osnovi estetske usmeritve, pa tudi ta je bila zelo ohlapna. Podobno bi sicer lahko trdili še za Muzino, če bi k sodelovanju pritegnila širši krog skladateljev. Poleg vzporednic s politično vsakdanjostjo in nihajočega dotoka informacij, ki je povzročil, da se povojna modernistična »katarza« pri nas ni zgodila, gre razloge morda iskati tudi v premisleku, ali sploh dosegamo kritično maso ustvarjalcev. $\mathrm{Ob}$ tako majhnem številu avtorjev in upoštevajoč splošni pojav osebnih slogov že od začetka 20. stoletja je namreč težko pričakovati, da bi se pojavila skupina globljih somišljenikov. V našem prostoru gre zato za posamezne glasove, ki so se združevali bolj zaradi neugodnih razmer za delo. Tako PMV kot Muzina sta združevali zelo različne ustvarjalce, ki jim je bilo skupno negiranje obstoječega in ne zagovarjanje kake »nove« glasbene ideje. Mogoče je še opaziti, da se v novem stoletju skladatelji ne združujejo več »samostojno« (z izjemo stanovskega društva), ampak se priključujejo pobudam institucij (na primer Cankarjevega doma s festivalom Predihano) ali izvajalcev (na primer ansambla Slowind) ali pa znotraj umetnostne glasbe in tudi izven nje iščejo nove komunikacijske poti. Morda pa je vredno razmisliti tudi v smeri, ki jo ob koncu svoje monografije nakaže O'Loughlin: po osamosvojitvi naj bi se razmere (vsaj navzven) izboljšale, past pa je v povečanem pritisku tržne

${ }^{47}$ Škrlj, »Pedagoški portret slovenske skladateljice Brine Jež Brezavšček«, 57.

${ }^{48}$ V navedeni diplomski nalogi se sicer na več mestih pojavi letnica 1999, a je verjetno 2000 zanesljivejša - najdemo jo na primer v predstavitvi skladateljice na spletni strani DSS ali v knjigi Nialla O’Loughlina.

${ }^{49}$ Torej ne drži popolnoma, kar navaja Brina Jež Brezavšček v pogovoru, in sicer, da je društvo ukinila sama.

${ }^{50}$ Križnar, »Poskus diagnoze sodobne slovenske glasbene umetnosti«, 41.

${ }^{51}$ Križnar, »Po prvem mednarodnem festivalu 'nove' glasbe Muzifest '99 Društva za vzpodbudo in napredek nove glasbe MUZINA«, 107. 
ekonomije na komercialno uspešnost, s čimer se zmanjšujejo možnosti za izvedbe tistih del, ki praviloma ne polnijo dvoran. ${ }^{52}$

\section{Primerjave in razlike med slovensko glasbo sedemdesetih in francoskim spektralnim gibanjem}

Programska politika je eden od ključnih dejavnikov pri usmerjanju glasbenega življenja in pripravlja »plodna tla« za vstopanje novih glasbenih idej. Slabše poznavanje sočasnih evropskih tokov je težava, ki je pestila tako skladatelje kot tudi muzikologe in kritike vsega povojnega obdobja. »Kulturni prostor je zato brez potrebnih predinformacij. Vsaka nova generacija ali usmeritev pride v prazen prostor in v njem obvisi. $\aleph^{53}$ Spektralne ideje ${ }^{54}$ zato v slovenski prostor niso vstopale prek izvedb temeljnih spektralnih skladb ali poznavanja ključnih besedil, ki niti slovenski muzikologiji niso bila znana, ${ }^{55}$ ampak najprej prek nekaterih skladateljev, ki jim je skupno to, da so se šolali ali dlje delovali v tujini ali so celo pri nas živeči tujci. Tudi pobuda za prvo izvedbo kakega spektralnega dela je prišla s strani skladatelja: na festivalu Slowind 2005 je bila namreč izvedena skladba Talea G. Griseya, umetniško vodstvo festivala pa je bilo tistega leta zaupano Nevillu Hallu, enemu prvih pri nas delujočih skladateljev, ki je spektralno mišljenje vgradil v svoj glasbeni jezik. Zavedanje o obstoju spektralne glasbe se tako pri nas pričenja šele sredi prvega desetletja 21. stoletja. ${ }^{56}$ Verjetno prva zabeležba musique spectrale v kakem slovenskem znanstvenem besedilu je v kontekstu obravnave »zgodovinske neumeščenosti« Rojkovih del - prispevek je izšel v monografiji Leona Stefanije leta 2010 ${ }^{57}$ Prvi poskus opredelitve pojma prihaja iz nemuzikoloških vrst: cikel radijskih oddaj o spektralni glasbi je leta 2008 pripravil Zlatko Kovačič, član Društva za razvoj humanistike Zofijini ljubimci. ${ }^{58}$

Zakaj pri nas ni opaziti niti zametkov rešitev, kakršne je v sedemdesetih letih narekoval »duh časa«? Taki zgodovinski premiki so se v 20. stoletju pojavili večkrat: v prvih desetletjih so sočasno in neodvisno potekala raziskovanja, ki so vodila k odmikom od tonalitetnosti in vključevanju mikrotonalnosti, po katastrofi druge svetovne vojne se je pojavila splošna potreba po prelomu s preteklostjo, tak prelomni trenutek pa so bila tudi sedemdeseta leta, ko se je povojni modernizem upehal: prav tako sočasno in neodvisno so se pojavljale rešitve, ki so bile usmerjene stran od organizacijskih sistemov in k fizikalnim lastnostim zvoka ter spoznanjem psihoakustike. Iskanja so zajela večino tistih,

${ }^{52}$ O’Loughlin, Novejša glasba v Sloveniji, 326-327.

${ }^{53}$ Lebič, »Glasovi časov«, 3:5.

${ }^{54}$ Termin »spektralna glasba« je precej izmuzljiv. Ni jasno, ali je mogoče govoriti le o skupnih izhodiščnih idejah, naboru značilnih kompozicijskih tehnik ali morda celo o kompozicijski šoli. Prim. Vrhunc, »'Spectral' aspects in Neville Hall's compositional thinking«, 218-220.

${ }_{55}$ Osebni pogovori in pregled temeljne slovenske literature.

${ }^{56}$ Nekateri v tujini delujoči ali šolajoči se skladatelji so se s spektralno glasbo seznanili že prej.

${ }^{57}$ Prim. Stefanija, Prispevek $k$ analizi, 87.

${ }^{58}$ Zlatko Kovačič, elektronsko sporočilo z dne 8. 8. 2014. Označi se za »naravoslovca z radovednostjo, potopljeno v družboslovje«. Oddaje o sodobni glasbi je pripravljal s sodelavcem Robertom Petrovičem (filozofom) za mariborski študentski radio MARŠ med leti 2006 in 2008. 
ki so imeli izkušnje v elektronskih studiih, pa tudi samohodce kot sta H. Radulescu ali G. Scelsi. L. Lebič je te premike označil kot »trud za večjo pripovedno zmogljivost glasbe «. ${ }^{59}$ Čeprav je imel bolj verjetno v mislih postopno semantiziranje glasbe, kot je značilno za njegove skladbe od tega časa naprej, bi v to kategorijo sodilo tudi upoštevanje percepcijskih zmožnosti poslušalca, s čimer so se ukvarjali na primer spektralni skladatelji. Lebič v nadaljevanju besedila poda tri kompozicijsko-tehnične spremembe, ki označujejo tudi spektralna iskanja: »povedne napetosti« med »sozvočji« in »razzvočji« V Lebičevi opredelitvi so napetosti med harmoničnimi in neharmoničnimi spektri na eni in zveznimi spektri oziroma šumi na drugi strani v spektralni glasbi, vračanje v metrične okvire in k manj kompleksnim ritmom ter forma, ki želi biti vsaj na površju prepoznavna, pa v spektralni glasbi predstavljata poudarjeno skrb za organizacijo glasbenega časa na mikro in makro ravni. Tudi v Lebičevi glasbi sami najdemo stičišče s spektralno prakso: G. Pompe opozori na vplive dela v elektronskem studiu v njegovih simfoničnih delih, ${ }^{60}$ enako pa seveda velja za vzornike spektralnih skladateljev G. Ligetija, I. Xenakisa, K. Stockhausna, pa tudi za njih same. ${ }^{61}$

»Duha časa« je bilo mogoče zaznati v tujini drugače kot pri nas, saj je šlo za reakcijo na obdobje, ki ga pri nas ni bilo. Srečali smo se že s slovensko povojno regresijo in slabo informiranostjo. Za francoske ustvarjalce pa so bile razmere ravno nasprotne: že v petdesetih letih so dobili koncertno združenje Domaine musical, ki ga je vodil P. Boulez in katerega programi so predstavljali najnovejša dela, elektronski studio GRM Pierra Schaefferja pa je bil eden najpomembnejših centrov zgodnje elektroakustične glasbe. Možnosti za obiske Darmstadta, Donaueschingena in drugih tujih najpomembnejših festivalov je bilo veliko. Čeprav se je spektralni »upor« zgodil več kot deset let za obdobjem, v katerem je delovala PMV, je vendarle to pri nas edina skupina, s katero je spektralno gibanje sploh mogoče primerjati. Glede na časovni zamik je razumljivo, da so se spektralni skladatelji upirali dogmatizmu prvega modernističnega vala. A PMV se mu tudi deset let kasneje ne bi mogla upreti, ker ga v resnici pri nas ni bilo. PMV si je za vzornika vzela S. Osterca in M. Kogoja, primerjave kompozicijskih tehnik obeh idolov z deli mladih skladateljev pa ne kažejo praktično nobenih podobnosti. Osterc in Kogoj sta bila »ideološki figuri, ki sta bili uporabni za vsakovrstno izkazovanje 'sodobnega' glasbenega koncepta in modernistične estetike. ${ }^{62}$ Naši skladatelji so poročali, da od učiteljev niso dobili nobenih koristnih informacij, ali pa so jih ti celo ovirali, logična posledica takega študija pa je bila, da so bile osebne poetike skupki naključnih okruškov najbolj raznorodnih tehnik. Družilo jih je le to, da so vsi odklanjali durovsko-molovske tonalitete in sistem kadenčnih formul. ${ }^{63} \mathrm{Na}$ drugi strani so pri spektralnih skladateljih vplivi vzornikov jasno vidni tudi na kompozicijsko-tehnični ravni, kar pomeni, da so dela dobro poznali. Za to se lahko

${ }^{59}$ Lebič, »Glasovi časov«, 4:59. Dejstvo, da je mogoče primerjati njegov opis splošnih pojavov s spektralnimi iskanji, kaže na to, da je tudi sam zaznal, v katero smer se glasba premika, a so šle njegove rešitve zaradi drugačnih ozadij po drugi poti.

${ }^{60}$ Pompe, »Elektroakustična glasba v Sloveniji nekoč in danes«, 9.

${ }^{61}$ E. Varèse je posebni primer: njegova dela kažejo, da je predvideval zmožnosti elektronskih naprav, še preden jih je lahko tudi preizkusil.

${ }^{62}$ Barbo, »Slavko Osterc kot mit avantgarde šestdesetih let«, 49.

${ }^{63}$ Barbo, Pro musica viva, 8 
zahvalijo izvrstnemu Messiaenovemu poučevanju: če slovenski skladatelji poročajo, da niso imeli dostopa do informacij in sploh niso mogli spoznati temeljnih modernističnih del, je O. Messiaen, nasprotno, poskrbel, da so se njegovi študenti ne samo seznanili z njimi, ampak so se lahko srečevali tudi z njihovimi avtorji, ki so prihajali predstavljat svoje ideje in odgovarjat na vprašanja radovedne mladine. ${ }^{64}$ Zato ne more čuditi, da so svoje združevanje poskušali utemeljiti na osnovi glasbeno-tehničnih in estetskih predpostavk.

Ogledali smo si nasprotja med obema skupinama, opaziti pa je mogoče tudi nekaj vzporednic: tako eni kot drugi so se najprej združevali zaradi študija. Slovenski skladatelji so se sestajali po kavarnah in domovih in skupaj preučevali glasbena dela ali zapise o njih. Francoski spektralni skladatelji so se večinoma spoznali že v času študija pri O. Messiaenu, druženje pa so nadaljevali v francoski rezidenci za umetnike, v Villi Médicis v Rimu. Če razumemo jedro spektralne glasbe kot skupino, ki se je izoblikovala okrog ansambla L'Itineraire, je vzporednic s PMV še več: obe skupini sta imeli svoje izvajalsko telo, s pomočjo katerega sta uresničevali svoje programske zamisli, obe sta si za cilj zadali tudi promocijo glasbe starejših vzornikov (L'Itineraire je Franciji predstavil glasbo G. Scelsija, PMV in kasneje ASO pa dela M. Kogoja in S. Osterca). Obe sta delovali približno eno desetletje in razpadli zaradi enakih razlogov: ni bilo več pravih razlogov za sodelovanje, saj so se medtem člani izoblikovali v zrele skladateljske osebnosti in se afirmirali. Interesi za združevanje so bili v obeh primerih (tudi) neglasbene narave: L'Itineraire je želel omajati Boulezov primat, PMV pa Škerjančevega. Poskušali so tudi jasneje deklarirati svoja stališča, pri čemer je skupina spektralnih skladateljev prišla dlje: pod vodstvom H. Dufourta so objavili kar dve besedili manifestativne narave, osnutek statuta PMV pa je ostal v Ježevem predalu.

Zanimiva je še ena neglasbena okoliščina: v Franciji je država finančno izdatno podprla najbolj radikalni modernizem ${ }^{65}$, pri nas pa je glasbeno kulturo podpirala neselektivno, po načelu »za vsakogar nekaj«.

\section{Literatura}

Barbo, Matjaž. Pro musica viva. Prispevek $k$ slovenski moderni po II. svetovni vojni. Ljubljana: Znanstveni inštitut Filozofske fakultete, 2001.

---. »Slavko Osterc kot mit avantgarde šestdesetih let«. Muzikološki zbornik 31 (1995): 47-51.

Beal, Amy C. »Negotiating cultural allies. American music in Darmstadt, 1946-1956«.

Journal of the American Musicological Society 53, št. 1 (2000): 105-139.

Bogunović Hočevar, Katarina. »Odmevi evropskih tendenc v ustvarjalnosti Janka Ravnika«. Doktorska disertacija, Univerza v Ljubljani, 2009.

Boivin, Jean. La classe de Messiaen. Paris: Christian Bourgois Éditeur, 1995.

${ }^{64}$ Prim. Boivin, La classe de Messiaen, 444-445.

${ }^{65}$ P. Bouleza je francoski predsednik G. Pompidou pooblastil tudi za ustanovitev in kasneje vodenje IRCAM, že pred tem pa je država podpirala tako Domaine musical kot GRM. 
Cvetko, Dragotin. Slovenska glasba v evropskem prostoru. Ljubljana: Slovenska matica, 1991.

Gačeša, Majeta. »Pro musica viva.« V: Odzven narave do zvezd. Zbornik Jakoba Ježa, uredila Marjeta Gačeša, 49-52. Ljubljana: Javni sklad Republike Slovenije za kulturne dejavnosti, 2015.

Klemenčič, Ivan. Slovenska glasba v evropskem okviru. Celje: Celjska Mohorjeva družba, 2008.

Koter, Darja. Slovenska glasba 1918-1991. Ljubljana: Študentska založba, 2012.

Kralj Bervar, Sonja. »Sobivanje družbenega, stanovskega in umetniškega v zgodovini Društva slovenskih skladateljev«. Doktorska disertacija, Univerza v Ljubljani, 2011.

Križnar, Franc. »Po prvem mednarodnem festivalu 'nove' glasbe Muzifest '99 Društva za vzpodbudo in napredek nove glasbe MUZINA«. Dialogi 35, št. 11-12 (1999): 106-109. »Poskus diagnoze sodobne slovenske glasbene umetnosti«. Dialogi 32, št. 5-6 (1996): 40-41.

Lebič, Lojze. »Glasovi časov. O slovenski glasbeni ustvarjalnosti«. 6 nadaljevanj. Naši zbori 45, št. 1-2 (1993): 1-5; št. 5-6 (1993): 111-118; Naši zbori 46, št. 1-2 (1994): 1-5; št. 3-4 (1994): 59-65; Naši zbori 48, št. 1-2 (1996): 1-6; št. 3-4 (1996): 50-54.

Loparnik, Borut. »Pogovor z Janezom Matičičem«. Nova revija 4, št. 43-44 (1985): 1469-1477.

O’Loughlin, Niall. Novejša glasba v Sloveniji. Osebnosti in razvoj. Prevedla Mojca Menart. Ljubljana: Slovenska matica, 2000.

Pompe, Gregor. »Elektroakustična glasba v Sloveniji nekoč in danes«. De musica disserenda 7, št. 2 (2011): 7-15.

---. »'Nove perspektive' v slovenski glasbi po letu 1945«. V: Roger Sutherland, Nove glasbene perspektive. Evropska in ameriška avantgarda v glasbi XX. stoletja, prevedla Gregor Pompe in Jure Potokar, 247-262. Ljubljana: LUD Šerpa, Slovensko muzikološko društvo, 2009.

Ross, Alex. Drugo je hrup. Poslušati dvajseto stoletje. Prevedel Leon Stefanija. Ljubljana: Beletrina, 2014.

Stefanija, Leon. Prispevek $k$ analizi institucij slovenske glasbe 20. stoletja. Ljubljana: Znanstvena založba Filozofske fakultete, 2010.

Škrlj, Darja. »Pedagoški portret slovenske skladateljice Brine Jež Brezavšček«. Diplomsko delo, Univerza v Ljubljani, 2013.

Vrhunc, Larisa. »'Spectral' aspects in Neville Hall's compositional thinking«. V: Music and its referential systems, uredila Matjaž Barbo in Thomas Hochradner, 217-234. Specula spectacula, 3. Dunaj: Hollitzer Wissenschaftsverlag, 2012. 


\section{THE RECEPTION OF SPECTRAL MUSIC WITHIN THE SLOVENIAN CULTURAL SPACE}

\section{Summary}

After the Second World War, composers took a turn away from their pre-war aesthetic orientation. Neoclassicism was a predominant form of aesthetics, partly due to the significant role played by politics at that time. None of the newly-established institutions assumed a leading role in ensuring a healthy musical life. This is why young composers during the first political thaw gathered at the Composers Club, and later formed the group Pro Musica Viva (PMV). PMV is the only group that has ever made an attempt to define itself aesthetically. Activities of the Collegium Musicum association were also fairly well-defined as far as its aesthetics were concerned, but this association was not exclusively made up of composers. Nevertheless, the 1950s and 1960s were a period of intensive pursuit of contact with contemporary European trends. Over the next decade, an 'intermediate' generation of composers came to maturity. Feeling no need to define their views in relation to the past or to current events, they did not make any attempts to form a group. This is partly due to the re-introduction of politics in art. This lethargic status quo was finally interrupted by Slovenia's independence, which further narrowed the cultural milieu and forced composers to search for different solutions. Thus, PMV is the only group in the post-war history of Slovenian music whose activities could be compared to the undertakings of the Paris group of spectral music composers in the 1970s. Their reasons for grouping and organizing around a performing body were similar, but there were differences in their working conditions and their broader cultural settings. Spectralist ideas have been brought to Slovenia by composers with close ties to foreign countries; however, no organized spectral music group has ever been formed. 